\title{
Does Exercise Affect Mental Health? (Study Sample: Athlete and Non-Athlete)
}

\author{
Hossein Karimi Pashaki ${ }^{1}$, Siavash Khodaparast ${ }^{2 *}$ and Vahid Bakhshalipour ${ }^{3}$ \\ ${ }^{1}$ Department of Physical Education and Sport Sciences, Karaj University Branch, Islamic Azad University, Iran \\ ${ }^{2}$ Department of Physical Education and Sport Science, Lahijan Branch, Islamic Azad University, Iran \\ ${ }^{3}$ Department of Physical Education and Sport Science, Payam Noor University, Iran
}

Submission: June 06, 2021; Published: July 14, 2021

*Corresponding author: Siavash khodaparast, Department of Physical Education and Sport Science, Lahijan Branch, Islamic Azad University, Guilan, Lahijan, Iran

\section{Abstract}

Aim: Promoting health and ensuring health in the community is one of the important pillars of the development of societies and it seems that important factors play a role in promoting the mental health of the community. Therefore, the purpose of this study is to investigate the effect of exercise on mental health.

Methodology: This study was a causal-comparative research that has been conducted through field method. The statistical population of this study was all students in Tarbiat Modares University that its non-athlete population was 6032 and its athlete population was 298.680 non-athlete students and 204 athlete students were selected as Morgan's table. The instrument of this study was included General Health Questionnaire (GHQ-28). The collected data were analyzed by Kruskal Wallis Test and Mann-Whitney U test.

Findings: The results showed that there was a significant difference between male and female athlete students and between female athlete and non-athlete students in social dysfunction subscale, so that female athlete students' social function had a better position in both groups. On the other hand, the difference between non-athlete female and male students was not significant in any of the subscales, but the difference between male athlete and non-athlete students was significant in all subscale of mental health. Other results of this study showed that there was a significant difference between married and single students' mental health $(\mathrm{p}<0.05)$, so that married students had higher mental health than single students in somatic symptoms, social dysfunction, and depression subscales.

Conclusion: Therefore, the increasing of motivation should be considered through the culture building and the promotion of general knowledge about the benefits of physical activity.

Keywords: Anxiety; Sleep disturbance; Social function; Depression

\section{Introduction}

The World Health Organization (WHO) considers health not merely the absence of disease, but as the complete and comprehensive physical, mental, and social well-being; According to this organization, a healthy person is one who can know himself, have optimal control and management of physical symptoms related to his psyche and the ability to cope with the normal stresses of life [1]. On the other hand, health is closely related to the characteristics of society and their social and economic structure, so that the main value of promoting knowledge and understanding in the field of determinants or social components of health goes back to the fact that social risk factors can be identified. , Are prevention and control, and in this way can be done by social interventions to reduce many diseases and mortality of high-risk groups in society and improve their quantity and quality of life and ultimately reduce health inequalities [2].

Today, the poor movement that has been created because of tremendous improvements in technology and mechanization of life and different jobs affects lifestyle in human societies. These very serious changes have had profound effects on human relationships at different levels of family and relationships with friends. If we look at human's physical construction, we will realize that human need naturally different kinds of physical activities for his/her entire development and evolution and the lack of adequate mobility and the lack of proper physical activities will disrupt different body systems. This great development in terms of health and well-being is one of the most important problems of today's 
human. This is very important for students, especially for students who are studying in a master's degree. Students should have a physical and mental health due to their role in social, cultural, and economic structures and their preparation to participate in social activities [2]. According to the World Health Organization (WHO), a person who does not have mental health is not considered a healthy person. This message is also approved by Pan American Health Organization and World Federation of Mental Health [3]. The mean of mental health is human's specific dimensions health such as intelligence, mind, and thought [4]. Mental health is one of the factors that can be effective in the dynamics and development of a community. Research evidence show some environmental controversies that affect students' mental health such as the desire for different social entertainments against willingness to study, the desire for physical superiority against organ limitations, the need to the lesson's development against the feel of incompetence, the fear of personality expression against the desire for self-esteem, and job selection [5,6]. According to researchers' idea who has mental health is a person that is distant from anxiety and disability symptoms, and she/he can establish a constructive relationship with others and is able to cope with life stresses [6,7]. On the other hand, conducted studies in the field of psychology and exercise have shown that exercise and physical activities are one of the effective methods for the prevention and treatment of mental illnesses [7]. Scientific evidence has shown that the participation in physical activities and the increasing of cardiovascular fitness are considered as an important factor in the improvement of mental health and mood [8]. Nine factors are important in the creation of happiness and mental health that the participation in physical activities and exercise is one of the most important factors [9]. Bakhshalipour et al. studied psychological and physical indexes in women that they concluded that aerobic activities and trainings had many benefits for behavior and mood. Also, they stated that physical activities were associated with the reduction of stress, tension, and the increasing of self-esteem [8]. Wang et al. (2004) expressed in their study that physical activity can play a role in the maintaining of securing mental health [10]. The results of their study showed that exercise played an important role in the change of the positive mood, self-satisfaction, sense of competence and efficiency that are components of individuals' mental health [10]. Conducted Studies by Ainsworth et al. (2005) showed that physical activity and exercise were effective on the promotion of mental health, the reduction of depression, and the increasing of well-being, mental and social health, selfesteem, and self-discovery [4]. On the other hand, there is a strong relationship between sleep quality and mental health. Also, the use of exercise is usually a non-drug strategy that can have beneficial effects on individuals sleep. Studies have shown that the use of physical activity is one of the most effective daily behaviors in the relationship with sleep quality and mental health. This study has compared male and female athlete and non-athlete students' mental health, since many researchers have emphasized the role of physical activity and exercise as an instrument for the prevention of diseases and mental disorders and due to the existence of significant differences in men and women's physiological characteristics. The study in this field is important that exercise, gender, and marital status may have different effects on students' mental health. According to the findings of this study and differences of effectiveness in students due to studied different factors, we hope that can provide more effective and coherent programs for more participation in sports activities of different groups with an attention to these differences to improve students' dimensions of mental health and the reduction of mental and psychological stresses in addition to the improvement of their physical abilities with the participation in sports activities.

\section{Materials and Methods}

The method of this study was casual comparative that has been conducted through field method.

\section{Participants}

The statistical population of this study was all students in Tarbiat Modares University who were studying for the master's degree and doctorate. The population of these students was 6337 that its non-athlete population was 3660 men and 2372 women, and its athlete population was 220 men non-athlete student and 78 women. The statistical sample of this study according to Morgan's table was included 350 male and 330 female nonathletes and 140 male and 64 female that they were selected by a random and stratified sampling.

\section{Instruments \& Tasks}

The instrument was included General Health Questionnaire (GHQ-28) that designed by Goldberg and Hiller (1979). It is a standard instrument that is used in 70 countries including in Iran [8]. The reliability of this questionnaire has been calculated 0.91 by Palahang et al. [11,12]. The used questionnaire in this study had four subscales and each subscale had 7 questions. These four subscales included: a) somatic symptoms, b) sleep anxiety and disturbance, C) social dysfunction, and d) depression symptoms. Different methods have been proposed for the scoring of test. Likert's method has been used in this study. According to this method, each answer scored zero to three (0-1-2-3). Each person's total score was obtained from the sum of scores of the four subscales (13).

\section{Procedure}

The purpose and the process of study were explained to subjects. The participants were assured that their data will be kept confidential and those will not be available to anyone. Then all subjects completed a consent form to participant in this study and they attended with the complete satisfaction in this study. The researcher distributed the questionnaires among the subjects. The subjects complete the questionnaires.

\section{Data Analysis}

The collected data were classified by descriptive statistical methods and were analyzed by Kruskal Wallis Test and MannWhitney U test $(\alpha \leq 0.05)$. 
Results

The results in Table 1 showed that there was a significant difference between male and female athlete students in the social dysfunction subscale $(\mathrm{P}<0 / 05)$, so that female athlete students had higher mental health than male athlete students. The results in Table 2 showed that there was no significant difference between male and female non-athlete students in the total score of mental health and somatic symptoms, sleep anxiety and disturbance, social dysfunction, and depression subscales $(\mathrm{P}>0.05)$.

Table 1: The related statistics to the comparison of mental health and its subscales between male and female athlete students.

\begin{tabular}{|c|c|c|c|c|}
\hline $\begin{array}{l}\text { Statistical Indexes } \\
\text { Mental Indexes }\end{array}$ & $\begin{array}{l}\text { Male Athlete } \\
\text { Rating Mean }\end{array}$ & $\begin{array}{c}\text { Female Athlete } \\
\text { Rating Mean }\end{array}$ & $\mathbf{Z}$ & Sig \\
\hline Mental Health & 103.28 & 100.8 & -27 & 0.78 \\
\hline Somatic symptoms & 96.66 & 111.23 & -1.63 & 0.1 \\
\hline Sleep Anxiety and Disturbance & 97.28 & 110.61 & -1.51 & 0.12 \\
\hline Social Dysfunction & 108.47 & 89.44 & -2.15 & $* 0.03$ \\
\hline Depression & 102.39 & 101.13 & -0.14 & 0.88 \\
\hline
\end{tabular}

Table 2: The related statistics to the comparison of mental health and its subscales between male and female non-athlete students.

\begin{tabular}{|c|c|c|c|c|}
\hline \multirow{2}{*}{ Statistical Indexes } & Male Athlete & Female Athlete & \multirow{2}{*}{ Z } & \multirow{2}{*}{ Sig } \\
\cline { 1 - 3 } Mental Indexes & Rating Mean & Rating Mean & -1.37 & 0.78 \\
\hline Mental Health & 202.95 & 186.95 & -1.2 & 0.23 \\
\hline Somatic symptoms & 202.11 & 188.19 & -1.57 & 0.11 \\
\hline Sleep Anxiety and Disturbance & 203.87 & 185.59 & -0.02 & 0.98 \\
\hline Social Dysfunction & 196.62 & 196.32 & -0.97 & 0.33 \\
\hline
\end{tabular}

The results in Table 3 showed that there was a significant difference between male athlete and non-athlete students in the total mean of mental health and somatic symptoms, sleep anxiety and disturbance, depression $(\mathrm{P}<0.01)$, and social dysfunction $(\mathrm{P}<0.05)$ subscales, so that male athlete students had higher mental health than male non-athlete students.

Table 3: The related statistics to the comparison of mental health and its subscales between male athlete and non-athlete students.

\begin{tabular}{|c|c|c|c|c|}
\hline Statistical Indexes & Male Athlete & Male Non-Athlete & Z & \multirow{2}{*}{ Sig } \\
\hline Mental Indexes & Rating Mean & Rating Mean & -3.9 & $0.001^{*}$ \\
\hline Mental Health & 159.33 & 204.35 & -4.37 & $0.001^{*}$ \\
\hline Somatic symptoms & 154.99 & 205.08 & -3.69 & $0.001^{*}$ \\
\hline Sleep Anxiety and Disturbance & 159.77 & 202.26 & -2.56 & $0.01^{* *}$ \\
\hline Social Dysfunction & 169.13 & 198.49 & -2.68 & $0.007^{*}$ \\
\hline
\end{tabular}

The results in Table 4 showed that there was a significant difference between female athlete and non-athlete students in the social dysfunction subscale $(\mathrm{P}<0.01)$, so that female athlete students had better social function than female non-athlete students.

The results in Table 5 showed that married students' rating mean of mental health was lower than single students' rating mean of mental health in all subscales that this difference was significant in mental health, social dysfunction, depression $(\mathrm{P}<0.01)$, and somatic symptoms $(\mathrm{P}<0.05)$ subscales. Therefore, married students had higher mental health than single students in these subscales. 
Journal of Physical Fitness, Medicine \& Treatment in Sports

Table 4: The related statistics to the comparison of mental health and its subscales between female athlete and non-athlete students.

\begin{tabular}{|c|c|c|c|}
\hline Statistical Indexes & Female Athlete & Female Non-Athlete & Rating Mean \\
\hline Mental Indexes & Rating Mean & 116.43 & -1.79 \\
\hline Mental Health & 99.34 & 113.27 & -0.64 \\
\hline Somatic symptoms & 107.14 & 112.73 & -0.18 \\
\hline Sleep Anxiety and Disturbance & 111 & 122.22 & -3.93 \\
\hline Social Dysfunction & 85.05 & 114.87 & -1.45 \\
\hline Depression & 101.29 & $0.001 *$ & 0.14 \\
\hline
\end{tabular}

Table 5: The related statistics to the comparison of mental health and its subscales between single and married students.

\begin{tabular}{|c|c|c|c|}
\hline Statistical Indexes & Single & Married & Rating Mean \\
\hline Mental Indexes & Rating Mean & 264.81 & Z \\
\hline Mental Health & 310.84 & 274.08 & -2.93 \\
\hline Somatic symptoms & 305.91 & 280.14 & -2.04 \\
\hline Sleep Anxiety and Disturbance & 303.56 & 265.33 & -1.5 \\
\hline Social Dysfunctio & 310.64 & 262.5 & -2.9 \\
\hline Depression & 311.07 & $0.004^{*}$ & -316 \\
\hline
\end{tabular}

\section{Discussion \& Conclusion}

The purpose of this study was to examine the effect of exercise on mental health in physical dimensions, anxiety, sleep disorder, social function, and depression in athlete and nonathlete students. The results of this study in the comparison of mental health mean in male and female athlete students and in female athlete and non-athlete showed that female athlete students had better performance in social function than male athlete and female non-athlete students. Fax and Matius have stated about the explanation of this result that female athlete who participate in a training program benefit physically and socially and they enjoy sports groups and new friendships [1315]. These interactions help to eliminate feelings and distractions and non-athlete women are deprived of the opportunity that physical activities provides for them [15]. Also, female athlete students' high social function than athlete male students may be due to men and women's different physiological characteristics including hormonal secretion and body composition [15]. that those can affect their physiological and social characteristics. This result is consistent with the results of Nasri and Vaez Mousavi's (2006) study. They studied sports coaches' mental health and concluded that female coaches' mental health were higher than male coaches [16]. Alizadehasli (2003) found different results [17]. He compared general health in athlete students that results showed that there was no significant relationship between gender and social dysfunction [17]. The importance of this issue is that physical education and sports programs can resolve some of these social needs in participants. The results of Tucker's study showed that physical fitness significantly reduced the risk of mental disorders in men and women [8]. The result of this study is consistent with the results of Bakhshalipour et al. (2017) study that they examined the effect of aerobic training on non-athlete postmenopausal women's mental health [5]. On the other hand, the difference in mean of mental health in the comparison of male and female athlete and non-athlete students did not show a significant difference in any of the subscales, but it was significant in all subscales with the comparison of male athlete and nonathlete students. So that male athlete students' mental health had better condition than the male non-athlete students. This result is consistent with the results of Khalaji et al. (2007) study [14]. They stated that male athlete students who participate regularly in physical activities such as walking, jogging, swimming, aerobics, or playing in sports teams can be able to do boring tasks in a longer period than inactive male students that this can be due to adaptive responses in a body because of regular exercise [14]. There is a lot of evidence about the benefits of regular physical activity for general health [17-20]. Studies show that intense and regular exercise is associated with less stress and anxiety. Also, people who participate in fitness and exercise programs report that their attitudes and efficiency are better at work, for example, they make less mistakes [20]. It seems that exercise can play an important role in students' physical and mental health due to all subjects are students who study at master's level, and they do many research works, and modern life conditions that have physical abnormalities such as back pain, joint damage, and diseases such as obesity and cardiovascular diseases. Therefore, the increasing of motivation through culture and the promotion of general knowledge about the benefits of physical activity can be considered as one of the options for the improvement of student sport. A program that may not have been seriously considered so far. The other result of this study was that there 
was a significant difference between married and single students in terms of mental health indexes $(\mathrm{P}<0.05)$, so that married students had better status than single students in mental health, social function, depression, and somatic symptoms subscales. One of the points that can be emphasized in the explanation of this conclusion is paying attention to the role of marriage in the supply of social support. The benefit of this support enables students to solve their problems more precise and more accurate and it will increase the happiness in students' life. Sarafino (2002) believes that social support from friends, family, and others leads to the reduction of mental stresses in people and it affects their mental health [21]. Hosseini and Hosseinchari (2004) compared some indexes of mental health in single and married students of Shiraz University [22]. They concluded that married students' total score of mental health (45.18) was lower than single students' total score of mental health (23.65). Also, married students' score in all subscales is lower than that single students' score that it indicates married students had higher mental health than single students [22]. This result is consistent with the results of Lynch (1990) study [23-31].

\section{References}

1. Lee CK, Hakjun S, Bernhard BJ (2013) The impact of CSR on casino employees' organizational trust, job satisfaction, and customer orientation: An empirical examination of responsible gambling strategies. International Journal of Hospitality Management 33: 406415.

2. Chen X, Wang P, Wegner R, Gong J, Fang X, et al. (2015) Measuring Social Capital Investment: Scale Development and Examination of Links to Social Capital and Perceived Stress. Soc Indic Res 120: 669-687.

3. Martin Prince, Vikram Patel, Shekhar Saxena, Mario Maj, Joanna Maselko, et al. (2007) No health without mental health. Global Mental Health 370(9590): 859-877.

4. Narimani M (2006) The comparison of general health in athlete and non-athlete students. The Third National Conference on Mental Health in students, Iran University of Science and Technology, pp. 360-364.

5. Bakhshalipour V, Sanatkaran A, Khodaparast Sareshkeh S, Zivdar Z, Azizi B (2017) The effectiveness of selected aerobic training on the mental health in non- athlete postmenopausal women. Sport Scientific and Practical Aspects. Sport SPA 14(1): 5-10.

6. Isfahani $\mathrm{N}$ (2002) The effect of exercise on mental health in physical dimension, anxiety, sleep disorder, social function, and depression in Alzahra University Students. Harakat (12): 75-86.

7. Kamau CW, Burnout (1992) locus of control and mental health of teachers in eastern province of Kenya, Unpublished PhD. Thesis in Education submitted in Punjab University Chandigarh, Chandigarh, pp. 123-129.

8. Goudarzi M, Hemayattalab R (2006) The comparison of happiness factors in individual and team athletes of Tehran University. Research on Sport Sciences 15: 57-66.

9. Hemayattalab R, Bazzazan S, Lahmi R (2003) The comparison of happiness and mental skills in female athlete and non-athlete students of Tehran Universities and Payame Noor Universities. Journal of Movement Science and Sport 18: 132-140.

10. Tasai Eva (2005) A cross cultural study of the influence of perceived positive outcome participation in regular active recreation: Hong Konand Australian University Students. Leisure 27(5): 385-404.
11. Kerlinger FN, Pedhazur EJ (1983) Multiple regression in behavioral research. New York: Holt, Rinehart, and Winston.

12. Mousavi J, Mozaffari AA (2007) The comparison of mental stress in athlete and non-athlete employees of Islamic Azad University Branches in the region 3 of country. Journal of Movement Science and Sport 9: 59-70.

13. Bakhshalipour V, Khodaparast Sareshkeh S (2020) The effect of physical activity on sleep and quality of life of inactive elderly men. Cjhaa 4(2): 56-65.

14. Nikgoftar M (2006) The role of emotional intelligence training on academic achievement and general health of students. Ph.D. thesis, Faculty of Humanities, Tarbiat Modares University, Iran, p. 115.

15. Khalaji h, Bahram A, Aghapour SM (2007) Fundamentals of Physical Education and Sport Science. Publication of Samt, Tehran, Iran.

16. Fax and Matius (1999) Sport Physiology (translated by Asghar Khaledan). ( $3^{\text {rd }}$ edn), Publication of Tehran University, Iran.

17. Nasri S, Vaez Mousavi MK (2006) The survey of mental health and quality of life in sports coaches of Iran. Research on Sport Sciences 4(13): 51-79.

18. Alizadehasli A (2003) The comparison of general health dimensions in athlete and non-athlete students of Shiraz University and its interactive relationship with gender. MA thesis in Educational Psychology, Shiraz University, Iran.

19. US Department of Health and Human Services (1996) Physical Activity and Health: A Report of the Surgeon General. Atlanta, GA: Centers for Disease Control and Prevention, National Center for Chronic Disease Prevention and Health Promotion.

20. Paffenbarger RS, Hyde RT, Wing AL, Hsieh CC (1986) Physical activity, all-cause mortality, and longevity of college alumni. New England Journal of Medicine 314(10): 605-613.

21. Kalashi M, Karimi pashaki H, Khodaparast S, Bakhshalipour V (2020) Relationship Between Social Capital Indicators and General Health of the Inactive Elderly Cjhaa 5(1): 45-52.

22. Sarafino EP (2005) Health Psychology (translated by Ahmadi Abhari A). Publication of Roshd, Tehran, Iran.

23. Sarafino EP (2002) Health Psychology Biopsychosocial Interactions. John Wiley \& Sons, INC.

24. Hosseini F, Hosseinchari M (2004) The comparison of some indexes of mental health in single and married students of Shiraz University. The Third National Conference on Mental Health in students, Iran University of Science and Technology, pp. 124-128.

25. Lynch JJ (1990) The broken heart: The Psychology of human contact. In: P Ornstein, C Swencionis (Eds.), The healing brain: A Scientific reader. New York: Guiford.

26. Berkman LF (1995) The role of social relations in health promotion. Psychology Review 48: 134-142.

27.Zahrakar K (2002) The role of marriage in mental health. Family counselor, pp. 238-239.

28. Bakhshalipour V, Khodaparast Sareshkeh M, Falah Kazemi M (2016) The effect of a moderate-intensity aerobic training program on the S Keramati Moghadam sleep quality, BMI, and weight in non-active people with type 2 diabetes. Sport Scientific and Practical Aspects Sport SPA 13(1): 13-18.

29. Bakhshalipour V, Khodaparast Sareshkeh, S, Falah Kazemi M, Keramati Moghadam M, Soleimani Keshayeh S (2016) The effect of regular moderate-intensity physical activity on sleep quality in non-active elderly women. IJPESH 3(3): 430-433. 
30. Bakhshalipour V, Khodaparast Sareshkeh S, Zivdar Z, Touba N (2016) The comparison of mental health between male athlete and non-athlete students in Islamic Azad University Branches of Guilan Province. Sport Scientific and Practical Aspects 13(2): 25-29.
31. Bakhshalipour V, Sanatkaran A, Rezaei Soufi M (2015) The effects of 4-week of aerobic exercise training on non-athlete male students sleep and life quality. IJBPAS Special Issue 4(12): 103-118.

\section{Your next submission with Juniper Publishers} will reach you the below assets

- Quality Editorial service

- Swift Peer Review

- Reprints availability

- E-prints Service

- Manuscript Podcast for convenient understanding

- Global attainment for your research

- Manuscript accessibility in different formats ( Pdf, E-pub, Full Text, Audio)

- Unceasing customer service

Track the below URL for one-step submission https://juniperpublishers.com/online-submission.php 